\title{
CONTROLLABILITY OF R.C. PANELS BEHAVIOR MODIFIED WITH OPTIMAL FIBER HYBRIDIZATION SYSTEM
}

\author{
Mahmoud Abo El-Wafa Ahmed \\ Post Doctor Fellow, Urban and Civil Engineering Dept., Ibaraki \\ University, Japan / Lecturer, Civil Eng. Dept., Faculty of Engineering, \\ South Valley University, Aswan, Egypt.
}

(Received February 26, 2008 Accepted March 15, 2008)

Recently, controllability is considered as an important concept in a science of concrete construction. In the light of that, if it is possible to guide a system to a certain state (favored condition) by controlling its inputs, the impending question is "what is the appropriate way to find the most efficient method of having this transformation?" One idea gaining much attention lately is that of fiber hybridization. In a hybrid, two or more different types of fibers are rationally combined to produce a composite that derives benefits from each of the individual fibers and exhibits a synergistic response. This paper focuses on the experimental investigation carried out on controllability of R.C. panels behavior modified with optimal fibers hybridization system (hybrid combination of steel and polypropylene fibers) up to a volume fraction of $1.0 \%$. Strengtheffectiveness on the mechanical properties, namely, compressive and splitting tensile strength as well as the behavior of R.C. panels modified with optimal fibers hybridization system were studied. The results clarify that the optimal fibers hybridization system is seen to enhance the strengtheffectiveness on mechanical properties, the controllability-efficient on R.C. panels behavior as cracking behavior, pre-peak as well as post-peak region of the load-deflection curve, causing an increase in flexural strength and toughness. Thus, the optimal fibers hybridization system has the potential advantages for large-scale use in concrete construction.

KEYWORDS: controllability-efficient, optimal fibers hybridization system, strength-effectiveness.

\section{INTRODUCTION}

Due to its brittle behavior and low tensile strength, concrete can crack when loaded. The consequences of concrete cracking behavior are aesthetical defects on concrete surfaces, increase of permeability, and reduction of mechanical section and reduction of steel reinforcement protection that can compromise concrete durability. Thus, controllability behavior of concrete construction is of interest for evaluation of durability performance and has become essential in order to maintain the integrity and aesthetics of concrete construction.

Short fibers are considered as one of the most exciting and promising materials that have the potential advantages for controllability behavior of concrete construction. When fiber reinforcement is added to concrete mixtures, the composite become 
tougher and stronger because of the additional increase in fracture due to the toughening effect of the fibers in front of the crack tip [1]. Therefore, fibers reinforcement resist the growth of cracks by acting as stress transfer bridges, and once cracks growth, fibers abate their propagation by providing crack tip plasticity and increased fracture toughness.

High elastic modulus of steel fibers enhances the flexural toughness and ductility of concrete construction. The contribution of steel fibers can be observed mainly after matrix cracking in concrete, in that they help in bridging the propagating cracks [2-4]. The addition of steel fibers at high dosages, however, has potential disadvantages in terms of poor workability and increased cost. In addition, due to the high stiffness of steel fibers, micro-defects such as voids and honeycombs could form during placing as a result of improper consolidation at low workability levels. A compromise to obtain good fresh concrete properties (including workability and reduced early age cracking) and good toughness of hardened concrete can be obtained by adding another type of fibers as polypropylene fibers, which can function individually at different scales to yield optimum performance.

The addition of polypropylene fibers results in good fresh concrete properties and reduced early age cracking. The beneficial effects of polypropylene fibers could be attributed to their high aspect ratios and increased fiber availability (because of lower density as compared to steel) at a given volume fraction. Because of their lower stiffness, this type of fiber is particularly effective in controlling the propagation of micro cracks in the plastic stage of concrete $[5,6]$. However, their contribution to postcracking behavior, unlike steel fibers, is not known to be significant.

Recently, controllability is considered as an important concept in a science of concrete construction. Intuitively, by means of the system inputs, a system is controllable if it is possible to change the state from any initial condition to any final favored condition. In the light of that, if it is possible to guide a system to a certain state by controlling its inputs, the impending question is "what is the appropriate way to find the most efficient method of having this transformation?"

Reinforcement of concrete with fibers, however, still remains a science in its infancy, and ideas are still evolving towards assessing the characteristics of an optimal fiber system. One idea gaining much attention lately is that of fiber hybridization. In a hybrid, two or more different types of fibers are rationally combined to produce a composite that derives benefits from each of the individual fibers and exhibits a synergistic response. The precise ways in which various fibers should be combined to produce a synergistic response, however, are not understood. This paper focuses on the experimental investigation carried out on controllability of R.C. panels behavior modified with optimal fibers hybridization system (hybrid combination of steel and polypropylene fibers) up to a volume fraction of $1.0 \%$.

Strength-effectiveness on the mechanical properties, namely, compressive and splitting tensile strength as well as the controllability-efficient on R.C. panels behavior modified with optimal fibers hybridization system were studied.

\section{EXPERIMENTAL PROGRAM}

The experimental program was designed to check the controllability of R.C. panels behavior modified with optimal fibers hybridization system (hybrid combination of 
steel and polypropylene fibers) up to a volume fraction of $1.0 \%$. For this purpose the R.C. panels had a $2000 \mathrm{~mm}$ total length with $400 \times 120 \mathrm{~mm}$ cross-section reinforced with a constant amount of steel bars $5 \phi 10$ as longitudinal reinforcement and $8 \phi 10$ as short reinforcement. The dimensions and reinforcement of all R.C. panels used in this study were constant, modified with individual fibers as steel fibers, polypropylene fibers and hybrid combinations of steel and polypropylene fibers up to a volume fraction of $1.0 \%$ were tested in four points bending test, as shown in Fig. 1.

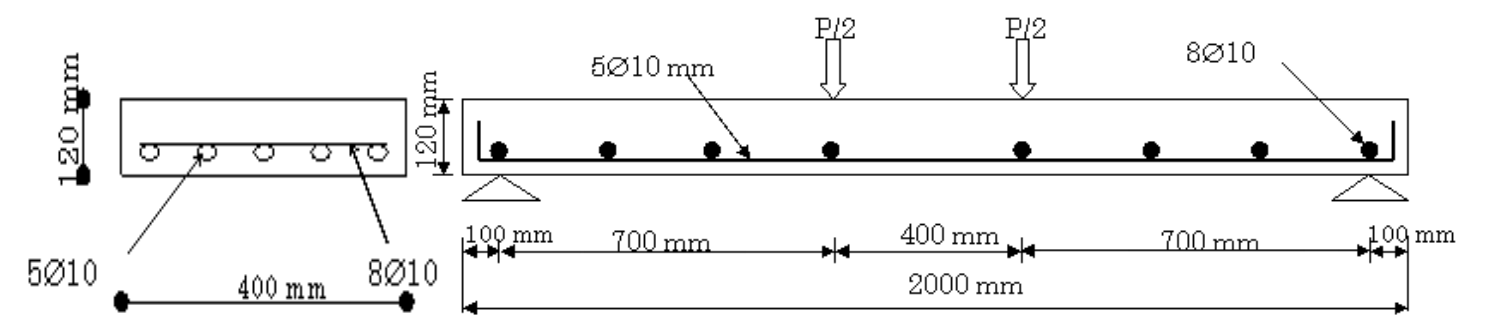

Fig. 1: Setup of R.C. panels composite tested in four points bending test

The fibers hybridization system (hybrid combination of steel and polypropylene fibers) involved combining fibers of similar sizes but different density, tensile strength and stiffness (Young's modulus). The R.C. panels composites modified with optimal fibers hybridization system are given in Table 1.

Table 1 R.C. panels composites modified with optimal fibers hybridization system
R.C. panels
Geometry of fibers
Volume fraction

$$
\begin{aligned}
& \text { RC.P-0 } \\
& \text { RC.P-SF }
\end{aligned}
$$

RC.P-PP

RC.P-SFPP

$$
\text { Steel fiber (SF) }
$$
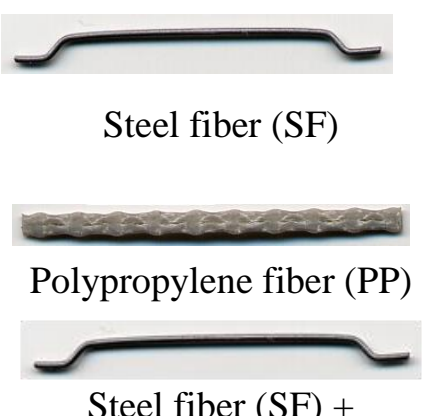

Steel fiber $(\mathrm{SF})+$

Polypropylene fiber (PP)
$0.0 \%$

$1.0 \%$

$1.0 \%$

$0.5 \%+0.5 \%$

\subsection{Materials and Mix proportioning}

The control concrete mix was specially designed to have a good workability and compressive strength of about $55 \mathrm{MPa}$ [7]. The concrete mixture proportion used in R.C. panels composites is presented in Table 2. 
Table 2 Concrete mixture proportion used in R.C. panels composites

\begin{tabular}{ccccc}
\hline $\begin{array}{c}\text { Cement } \\
\left(\mathrm{Kg} / \mathrm{m}^{3}\right)\end{array}$ & $\begin{array}{c}\text { Fine aggregate } \\
\left(\mathrm{Kg} / \mathrm{m}^{3}\right)\end{array}$ & $\begin{array}{c}\text { Coarse aggregate } \\
\left(\mathrm{Kg} / \mathrm{m}^{3}\right)\end{array}$ & $\begin{array}{c}\text { Water } \\
\left(\mathrm{Kg} / \mathrm{m}^{3}\right)\end{array}$ & $\begin{array}{c}\text { Superplast- } \\
\text { icizer } \\
\left(\mathrm{Kg} / \mathrm{m}^{3}\right)\end{array}$ \\
\hline 450 & 590 & 1180 & 175.5 & 4.5
\end{tabular}

Ordinary portland cement with 3.15 specific gravity was used for the concrete mixtures. Sand with a specific gravity of 2.55 and fineness modulus of 2.6 was used as the fine aggregate, while crushed basalt of specific gravity 2.65 was used as coarse aggregate. Superplasticizer was used in all mixtures to obtain the desired workability as $1.0 \%$ of the total cement.

The fibers used in the present study were steel fiber (SF) as hooked end type and polypropylene fiber (PP) as rod type. Physical and mechanical properties of the fibers used (steel and polypropylene fibers) are shown in Table 3.

Table 3 Physical and mechanical properties of the fibers used

\begin{tabular}{|c|c|c|c|c|c|}
\hline Geometry of fibers & $\begin{array}{l}\text { Diameter } \\
(\mathrm{mm})\end{array}$ & $\begin{array}{l}\text { Length } \\
(\mathrm{mm})\end{array}$ & $\begin{array}{l}\text { Density } \\
\left(\mathrm{g} / \mathrm{cm}^{3}\right)\end{array}$ & $\begin{array}{l}\text { Tensile } \\
\text { strength } \\
(\mathrm{MPa})\end{array}$ & $\begin{array}{l}\text { Young's } \\
\text { modulus } \\
(\mathrm{GPa})\end{array}$ \\
\hline $\begin{array}{c}\text { Steel fiber (SF) } \\
\text { Hooked end type }\end{array}$ & 0.60 & 30 & 7.8 & 2000 & 200 \\
\hline $\begin{array}{l}\text { Polypropylene fiber (PP) } \\
\text { Rod type }\end{array}$ & 0.60 & 30 & 0.91 & 750 & 10 \\
\hline
\end{tabular}

\subsection{Mixing, Casting Details and Testing Methodology}

The coarse aggregate, fine aggregate and cement were first mixed dry in a pan mixer for a period of $2 \mathrm{~min}$. The superplasticizer was then mixed thoroughly with the mixing water and added to the mixer. Fibers were dispersed by hand in the mixture to achieve a uniform distribution throughout the concrete, which was mixed for a total of $4 \mathrm{~min}$. Fresh concrete was cast in steel moulds and compacted on a vibrating table. The following specimens were prepared: three cubes $100 \mathrm{~mm}$ for compressive strength, three cylinders $\$ 100 \times 200 \mathrm{~mm}$ for splitting tensile strength and four R.C. panels with dimensions and reinforcement modified with optimal fibers hybridization system mentioned above. A universal testing machine of capacity 100 ton was used for testing the compressive strengths of cube specimens as well as splitting tensile strengths of cylindrical specimens at 28 days from the day of casting. The four R.C. panels were tested in four points bending static test as shown in Fig. 1. The mid-span deflection was measured using a dial gage accurate to $0.01 \mathrm{~mm}$, crack width at failure was measured using a crack microscope reading to $0.02 \mathrm{~mm}$, first crack load, and ultimate load capacity were recorded. 


\section{RESULTS AND DISCUSSION}

The results obtained from the experimental investigations are tabulated in tables and the comparisons are presented in form of graphs and bar charts. All the values are the average of the three identical specimens tested in each case during the compressive and splitting tensile tests. The results are discussed as follows.

\subsection{Strength-Effectiveness}

Table 4 and Fig. 2 present the strength-effectiveness on mechanical properties, namely, compressive and splitting tensile strength at 28 days of control concrete and concrete composite modified with individual fibers as steel fibers, polypropylene fibers and hybrid combinations of steel and polypropylene fibers up to a volume fraction of $1.0 \%$.

Table 4 Strength-Effectiveness on compressive and splitting tensile strength

\begin{tabular}{c|c|c|c|c}
\hline \multirow{2}{*}{$\begin{array}{c}\text { Concrete } \\
\text { composites }\end{array}$} & \multicolumn{2}{|c|}{ Compressive strength } & \multicolumn{2}{c}{ Splitting tensile strength } \\
\cline { 2 - 5 } & Measured (MPa) & $\begin{array}{c}\text { Strength- } \\
\text { Effectiveness* (\%) }\end{array}$ & Measured (MPa) & $\begin{array}{c}\text { Strength- } \\
\text { Effectiveness* (\%) }\end{array}$ \\
\hline $\begin{array}{c}\text { Control } \\
0.0 \%\end{array}$ & 55 & --- & 4.1 & -- \\
\hline $\begin{array}{c}\text { Modified with } \\
\text { SF-1.0\% }\end{array}$ & 61.3 & 11.5 & 5.4 & 31.7 \\
\hline $\begin{array}{c}\text { Modified with } \\
\text { PP-1.0\% }\end{array}$ & 60.6 & 10.2 & 5.2 & 26.8 \\
\hline $\begin{array}{c}\text { Modified with } \\
\text { SF0.5\%+PP0.5\% }\end{array}$ & 63.5 & 15.5 & 5.9 & 43.9 \\
\hline
\end{tabular}

Strength-Effectiveness $*(\%)=$ (Modified with fibers strength - Control strength $) /($ Control strength $)$

From the results of strength-effectiveness on compressive strength and splitting tensile strength, it is evident that an enhancement in strength-effectiveness compared to control concrete occurs with all concrete composite modified with fibers. However, for fiber concretes, the maximum increase of strength-effectiveness on splitting tensile strength were found to be higher of about (30-45\%) compared to on compressive strength that only of the order of about (10-16\%). In addition, it can be seen that the difference in performance of the hybrid fiber concretes (hybrid combination of steel and polypropylene fibers) that have a pronounced effect on strength-effectiveness compared to concretes with individual of either steel fibers or polypropylene fibers. The reason could be due to a combination of higher and smaller density of steel and polypropylene fibers, respectively, which give high availability reinforcement index. In addition, the high availability reinforcement index fibers make it more efficient in delaying the growth of micro and macro cracks and thereby improving the strength-effectiveness on compressive and splitting tensile strength. Therefore, the hybrid fiber concretes (hybrid combination of steel and polypropylene fibers) are important to have a combination of higher and smaller density fibers to arrest the micro and macro cracks, respectively. 


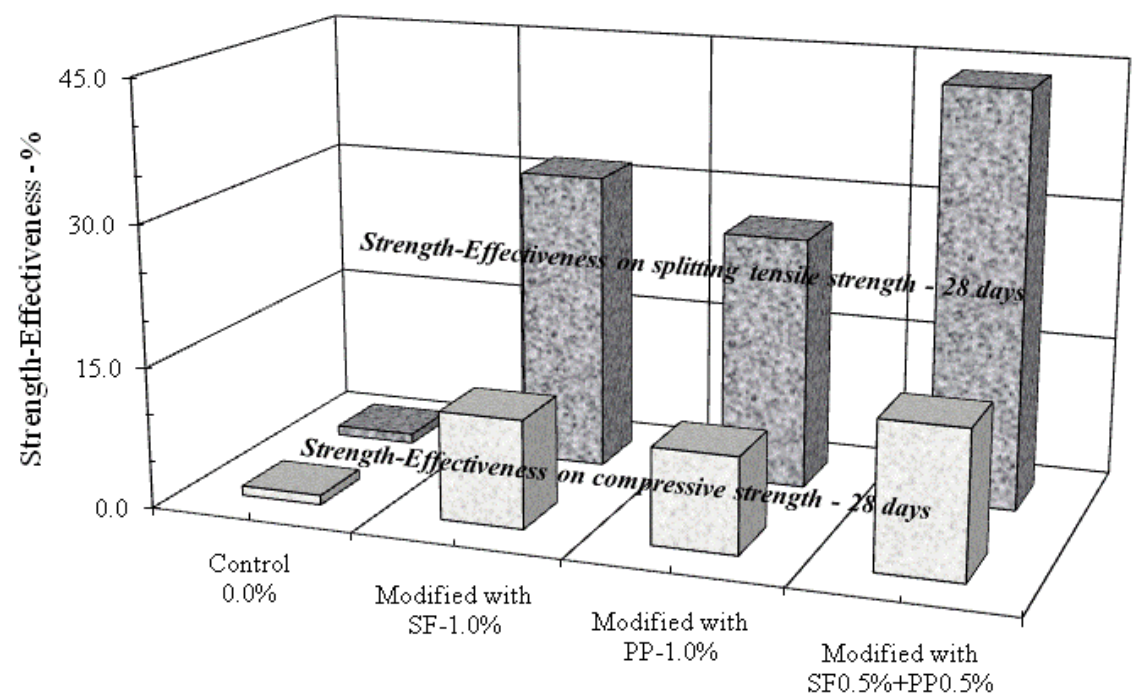

Fig. 2: Strength-Effectiveness on compressive and splitting tensile strength

\subsection{Controllability-Efficient on R.C. Panels Behavior}

The controllability-efficient on R.C. panels behavior as cracking behavior, pre-peak as well as post-peak region of the load-deflection curve, causing an increase in flexural strength and toughness are presented in Fig. 3 and Table 5.

The trends of the load-deflection curves observed in Fig. $\mathbf{3}$ indicate that all R.C. panels modified with fibers yield at a higher flexural toughness compared to control R.C. panel without fibers. Compared to all R.C. panels modified with fibers, only the hybrid combination of steel and polypropylene fibers is tougher, indicating a possible synergy in the action of these two fibers than the individual of either steel or polypropylene fibers. The result seems to indicate that the post-peak behavior, which contributes mainly to the difference in flexural strength and toughness between the control R.C. panel without fibers and all R.C. panels modified with fibers, is mainly dominated by the hybrid combination of steel and polypropylene fibers.

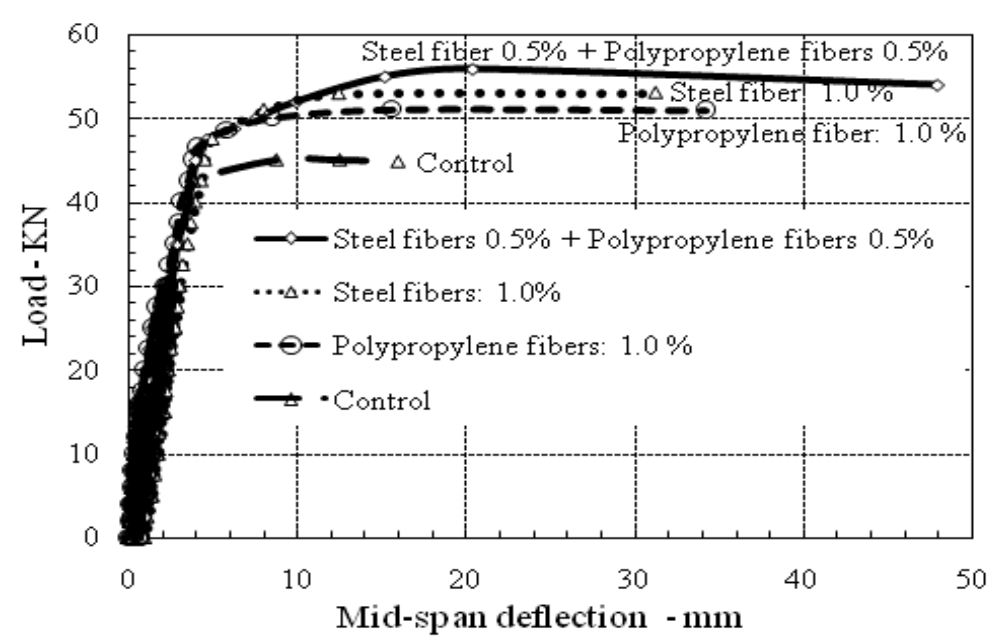

Fig. 3: Load-deflection curves of R.C. panels modified with fibers hybridization system 
Compared to control R.C. panel without fibers and all R.C. panels modified with fibers show an appreciable enhancement of the controllability-efficient on R.C. panels behavior, as shown in Table 5. Among all fiber R.C. panels, only the hybrid combination of steel and polypropylene fibers demonstrates the maximum controllability-efficient on R.C. panels behavior compared to R.C. panels with individual of either steel or polypropylene fibers.

Table 5 Controllability-Efficient on R.C. Panels Behavior

\begin{tabular}{c|c|c|c|c|c|c|c|c}
\hline \multirow{2}{*}{$\begin{array}{c}\text { Concrete } \\
\text { composites }\end{array}$} & \multicolumn{2}{|c|}{ First crack load } & \multicolumn{2}{c|}{ Ultimate load capacity } & \multicolumn{2}{c|}{ Max. deflection } & \multicolumn{2}{c}{ Max. crack width } \\
\cline { 2 - 9 } & $\begin{array}{c}\text { Measured } \\
(\mathrm{KN})\end{array}$ & $\begin{array}{c}\text { Controllability- } \\
\text { Efficient* } \\
(\%)\end{array}$ & $\begin{array}{c}\text { Measured } \\
(\mathrm{KN})\end{array}$ & $\begin{array}{c}\text { Controllability- } \\
\text { Eficient* } \\
(\%)\end{array}$ & $\begin{array}{c}\text { Measured } \\
(\mathrm{mm})\end{array}$ & $\begin{array}{c}\text { Controllability- } \\
\text { Efficient* } \\
(\%)\end{array}$ & $\begin{array}{c}\text { Measured } \\
(\mathrm{mm})\end{array}$ & $\begin{array}{c}\text { Controllability- } \\
\text { Efficient* } \\
(\%)\end{array}$ \\
\hline $\begin{array}{c}\text { Control } \\
0.0 \%\end{array}$ & 18 & --- & 45 & --- & 16 & -- & 0.22 & --- \\
\hline $\begin{array}{c}\text { Modified with } \\
\text { SF-1.0\% }\end{array}$ & 20 & 10 & 54 & 20 & 31.25 & 95.3 & 0.18 & 18.2 \\
\hline $\begin{array}{c}\text { Modified with } \\
\text { PP-1.0\% }\end{array}$ & 19 & 5.6 & 52 & 15.6 & 34.2 & 113.8 & 0.2 & 9.1 \\
\hline $\begin{array}{c}\text { Modified with } \\
\text { SF0.5\%+PP0.5\% }\end{array}$ & 22 & 22.2 & 57 & 26.7 & 48 & 200 & 0.16 & 27.3 \\
\hline
\end{tabular}

Controllability-Efficient* $(\%)=($ Modified with fibers - Control $) /($ Control $)$

The reason could be due to a combination of higher and smaller density of steel and polypropylene fibers, respectively, which give a high availability reinforcement index. In addition, the high availability reinforcement index fibers make it more efficient in delaying the growth of micro and macro cracks and thereby improving the controllability-efficient on R.C. panels behavior, as observed in the case of strength-effectiveness on the compressive and splitting tensile strength. Moreover, the combination of the lower stiffness (Young's modulus) of polypropylene fibers that are particularly effective in controlling the propagation of micro cracks in the plastic stage of concrete followed by the higher stiffness (Young's modulus) of steel fibers that can be observed mainly after matrix cracking in concrete, in that they help in bridging the propagating cracks. Thus, the hybrid fiber concretes (hybrid combination of steel and polypropylene fibers) are important to have a combination of higher and lower stiffness (Young's modulus) fibers to arrest the micro and macro cracks, respectively.

\section{CONCLUSIONS}

The results clarify that the optimal fibers hybridization system is seen to improve the strength-effectiveness on mechanical properties, namely, compressive and splitting tensile strength as well as an appreciable enhancement of the controllability-efficient on R.C. panels behavior as cracking behavior, pre-peak, post-peak region of the loaddeflection curve, causing an increase in flexural strength and toughness due to the hybrid fiber concretes (hybrid combination of steel and polypropylene fibers) give the high availability reinforcement index and are important to have a combination of the higher and lower stiffness (Young's modulus) fibers to arrest the micro and macro cracks, respectively. Thus, the optimal fibers hybridization system has the potential advantages for large-scale use in concrete construction. 


\section{REFERENCES}

1- Sivakumar, A., and Santhanam, M.: "Mechanical Properties of High Strength Concrete Reinforced with Metallic and Non-Metallic Fibers", Journal of Cement and Concrete Research, Vol. 29, pp. 603-608, (2007).

2- Song, P.S., and Hwang, S.: "Mechanical Properties of High-Strength Steel FiberReinforced Concrete", Construction and Building Materials Journal, ELSEVIR, PP. 669-673, (2004).

3- Hsu, L.S., and Hsu, T.: "Stress-Strain Behavior of Steel-Fiber High-Strength Concrete Under Compression”, ACI Structural Journal, Vol. 91, No. 4, pp. 448457, (1994).

4- Chunxiang, Q., and Patnaikuni, I.: "Properties of High-Strength Steel FiberReinforced Concrete Beams in Bending", Journal of Cement and Concrete Research, Vol. 21, No. 1, pp. 73-81, (1999).

5- Roesler, J., Salah, A., David. A., Klaus-Alexander, R., and Gregory, R.: "Effect of Synthetic Fibers on Structural Behavior of Concrete Slabs-on-Ground," ACI Materials Journal, Vol. 103, No. 1, pp. 3-10, (2006).

6- Bayasi, Z., and Zeng, J.: "Properties of Polypropylene Fiber Reinforced Concrete", ACI Materials Journal, Vol. 90, No. 6, pp. 605-610, (1993).

7- ACI Committee 544, "Measurement of Properties of Fiber Reinforced Concrete", ACI Materials Journal, Vol. 85, No.6, pp. 583-593, (1988).

\section{قابليه التحكم في سلوك الخرسانة المسلحة باستخدام النظام الأمثل لتهجين الأليافِ}

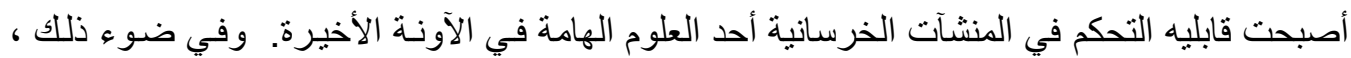

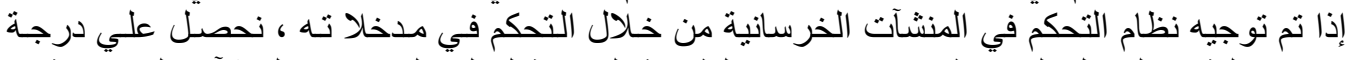

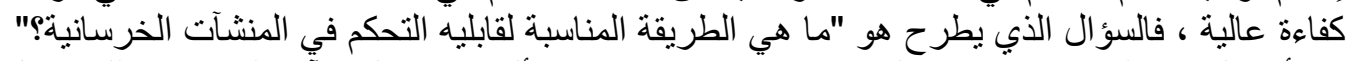

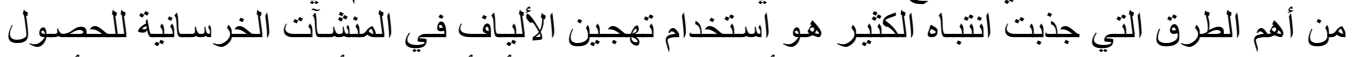

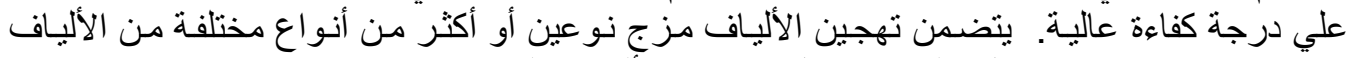

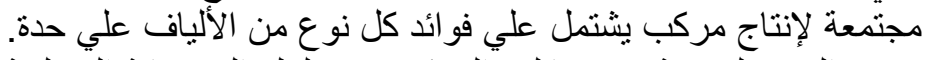

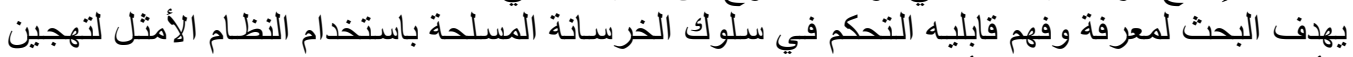

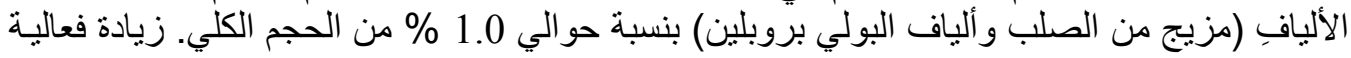

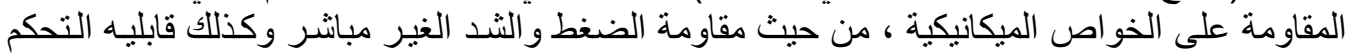
في سلوك الخرسانة المسلحة.

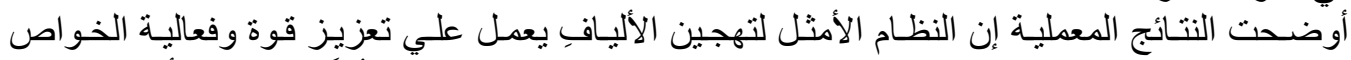

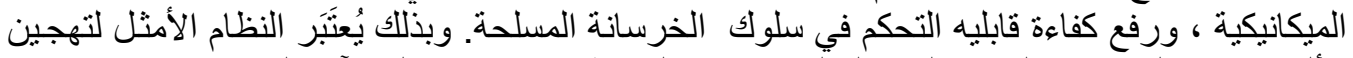

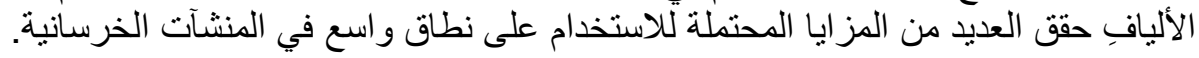

